This document is a manuscript version of the following article:

Title: A facility for testing the aerodynamic and acoustic performance of bidirectional air turbines for ocean wave energy conversion

By: Moisel, Christoph; Carolus, Thomas

Published in: Renewable Energy

Volume 86, February 2016, Pages 1340-1352

Publisher: Elsevier | Year: 2016

DOI: 10.1016/j.renene.2015.09.062

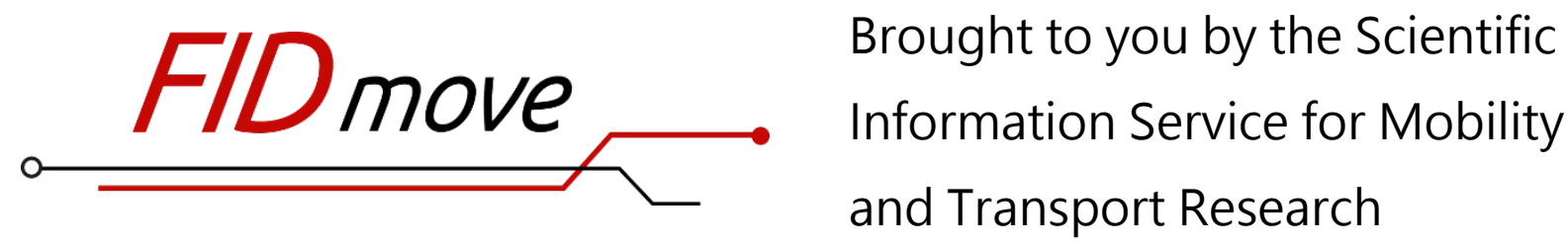

Fachinformationsdienst Mobilitäts- und Verkehrsforschung

Website: www.fid-move.de

Repository: publish.fid-move.de

Contact: publish@fid-move.de

(C) 2016. This manuscript version is made available under the CC-BYNC-ND 4.0 license.

http://creativecommons.org/licenses/by-nc-nd/4.0/ 


\title{
A Facility for Testing the Aerodynamic and Acoustic Performance of Bidirectional Air Turbines for Ocean Wave Energy Conversion
}

\author{
Christoph Moisel \\ Institut für Fluid und Thermodynamik \\ University of Siegen \\ 57068 Siegen, Germany \\ Email: christoph.moisel@uni-siegen.de
}

\author{
Thomas H. Carolus \\ Institut für Fluid und Thermodynamik \\ University of Siegen \\ 57068 Siegen, Germany \\ Email: thomas.carolus@uni-siegen.de
}

\begin{abstract}
Bidirectional air turbines are used in oscillating water column (OWC) power plants for harnessing ocean wave energy. This paper describes the bidirectional aerodynamic and aero-acoustic facility at the University of Siegen for model air turbines performance testing. At least nine test facilities are known worldwide, but their layout, the performance testing procedure and the presentation of performance data are not standardized to this day. The layout of the facility at the University of Siegen follows ideas in ISO 5801 for fan performance testing. The pressurized air supply is bidirectional but steady-state. Achievable values of Reynolds and Mach number of the test turbines are 1,000,000 and 0.5 , respectively. In addition, the facility is equipped with acoustic attenuators in the air supply for allowing synchronous determination of aerodynamic and acoustic characteristics of a turbine. A good practice guideline for turbine performance testing and presentation is proposed by showing full sets of non-dimensional aerodynamic and acoustic performance characteristics from two sample model turbines. Eventually, a comparison of in situ data from a full-scale turbine in transient operation with scaled up steady-state model performance measurements underlines the usefulness of steady-state model performance testing.
\end{abstract}

Key words: Performance testing facility, bidirectional air turbine, oscillating water column (OWC), wave energy, Wells turbine

\section{Nomenclature}

\begin{tabular}{|c|c|c|}
\hline A & cross-sectional area of turbine $\left[\mathrm{m}^{2}\right]$ & diameter ratio [-] \\
\hline $\mathrm{C}$ & nozzle coefficient [-], chord length [m] & pressure coefficient [-] \\
\hline $\mathrm{D}$ & diameter $[\mathrm{m}]$ & isentropic exponent [-] \\
\hline $\mathrm{Ma}$ & circumferential Mach number [-] & power coefficient [-] \\
\hline $\mathrm{L}$ & axial length of turbine $[\mathrm{m}]$, sound level $[\mathrm{dB}]$ & efficiency $[-]$ \\
\hline $\mathrm{P}$ & power $[\mathrm{W}]$, measurement plane & density $\left[\mathrm{kg} / \mathrm{m}^{3}\right]$ \\
\hline $\mathrm{R}$ & ideal gas constant & kinematic viscosity $\left[\mathrm{m}^{2} / \mathrm{s}\right]$ \\
\hline $\operatorname{Re}$ & Reynolds number [-] & KImematic viscosstly $[\mathrm{mi} / \mathrm{s}]$ \\
\hline $\mathrm{T}$ & torque $[\mathrm{Nm}]$, temperature $[\mathrm{K}]$ & Subscripts \\
\hline U & uncertainty [-] & C combined \\
\hline$\&$ & volume flow rate $\left[\mathrm{m}^{3} / \mathrm{s}\right]$ & full scale \\
\hline $\mathrm{X}$ & variable & Venturi nozzle \\
\hline $\mathrm{Y}$ & quantity & random \\
\hline $\mathrm{c}$ & absolute flow velocity $[\mathrm{m} / \mathrm{s}]$ & critical value \\
\hline $\mathrm{f}$ & frequency $[\mathrm{Hz}]$, function $[-]$ & meridional \\
\hline $\mathrm{n}$ & rotational speed [rps] & relative \\
\hline $1 \&$ & mass flow rate $[\mathrm{kg} / \mathrm{s}]$ & rotor tip \\
\hline $\mathrm{p}$ & static pressure $[\mathrm{Pa}]$ & total to static \\
\hline $\mathrm{r}$ & radius $[\mathrm{m}]$ & sound \\
\hline $\mathrm{t}$ & temperature $\left[{ }^{\circ} \mathrm{C}\right]$, time $[\mathrm{s}]$ & sound power \\
\hline $\mathrm{u}$ & circumferential velocity $[\mathrm{m} / \mathrm{s}]$ & \\
\hline $\mathrm{W}$ & relative velocity & Abbreviations \\
\hline$\beta$ & diameter ratio [-] & Oscillating Water Column \\
\hline$\Delta \mathrm{p}$ & differential pressure $[\mathrm{Pa}]$ & Reference Sound Source \\
\hline$\varepsilon$ & compression coefficient [-] & maxpower maximum power production \\
\hline$\phi$ & flow rate coefficient [-] & opt maximum peak efficiency \\
\hline
\end{tabular}




\section{Introduction}

The oscillating water column (OWC) is one of the most intensively studied principles for power plants that can harness the energy of ocean waves. An OWC consists of a semi-submerged water-air chamber with an opening to the sea beneath the water level as a wave collector. The approximately sinusoidal surface motion of the waves entering the chamber acts similar to a piston in a positive displacement machine and causes a bidirectional air flow through an upper opening of the chamber. The pneumatic power of this airflow is then used to drive an air turbine and eventually to generate electric power. Since it is desirable to maintain the rotational direction of the turbine throughout a wave cycle, bidirectional air turbines are installed in most OWC power plants. Over the last decades different types of bidirectional turbines have been developed, either non-zero or zero reaction type. (The reaction indicates the drop in pressure across the rotor compared to that for the complete turbine, DIXON [1]). The non-zero reaction turbines such as the axial-flow WELLS turbine require airfoil-type blades with their lift being a key parameter. The relative flow in the rotor is accelerated and the pressure drop across the rotor is substantial. Often these turbines are called "reaction type". In contrast, a zero reaction turbine requires highly cambered rotor blades that deflect the relative flow but do not accelerate it greatly. The pressure change through the rotor itself is small. However, the flow in zero reaction type turbines needs to be accelerated in guide vanes or nozzles. Frequently these turbines are called "impulse type".

Mature tools such as flow simulation methods are available and widely used for turbine design. Nevertheless, at the end of any design cycle the performance of a turbine has to be determined experimentally. Focusing exclusively on the flow rate, shaft torque and power yield of the turbine vs. pressure head - and hence disregarding the electrical part of the turbine - one faces at least three problems carrying out experimental performance tests:

(i) Differences obtained by testing the same turbine on various test facilities (in situ or laboratory); reasons are installation effects induced by each test facility causing different flow patterns at the turbine in- and outlet.

(ii) In laboratory tests the turbine investigated is often a scaled-down model of the full-scale turbine. Model tests require similarity between model and full-scale turbine - strictly speaking geometrical, kinematic and dynamic similarity has to be ensured. Geometrical similarity can be obtained by careful design and manufacture of the model including adequate tolerances - even surface finish may be of importance [2,3]. Full kinematic and dynamic similarity is more difficult to achieve. Reynolds and Mach number of both model and full-scale turbine must be equal, among others. In most model tests this is difficult to achieve.

(iii) Transient operation of the turbine in an OWC vs. steady-state testing; a turbine in an OWC experiences a cyclic variation of pressure head and a complete reverse of the flow direction during each period. It is an ongoing discussion in the community whether this transient operation has an impact of the performance characteristics of the turbine.

Tab. 1 lists various strategies of experimental bidirectional turbine performance testing. The listed advantages and disadvantages can explain why, during the last decade, a variety of turbine test methods and test facilities had been described and used by various authors and research establishments worldwide, Tab. 2. The rotor diameter and achievable values of Reynolds and Mach number are indicating the size of each test facility turbine section and hence possible constraints. Apparently approximately half of the test facilities allow only unidirectional and steady-state testing of the turbine, the other half bidirectional and cyclic. With the exception of the University of Siegen test facility none of the facilities allows measuring the sound emitted by the test turbine. Clearly, in contrast to e.g. the industrial fan sector with its long history of standardized performance testing (see e.g. ISO 5801: Industrial fans - performance testing using standardized airways [4] or ISO 13347-1 to -4: Industrial fans - determination of fan sound power levels under standardized laboratory conditions [5]) performance testing of bidirectional air turbines is not standardized. As a consequence published performance curves are difficult to compare. Moreover, how the full-scale turbine will perform in its target installation, driven by the real pressure head due to ocean waves, is problematic to predict.

A first objective of this paper is a detailed description of the present test facility for bidirectional model air turbines at the University of Siegen. This test facility is based on an earlier, less sophisticated facility (last test rig in Table 1) that underwent essential upgrading in the past years. The design philosophy follows ISO 5801 for fan performance testing. With the aid of this test facility the performance of turbines as large as the dual-stage axialflow Wells turbine with a rotor diameter $1.25 \mathrm{~m}$ and guide vanes, depicted in Fig. 1, is to be predicted accurately. A second objective is to propose a good practice guideline for bidirectional air turbine testing and presentation of performance data. 
Table 1

Experimental methods of bidirectional turbine performance testing

\begin{tabular}{|c|c|c|c|c|}
\hline Turbine & $\begin{array}{l}\text { Test } \\
\text { facility }\end{array}$ & $\begin{array}{l}\text { Pressure } \\
\text { head }\end{array}$ & Advantages & Disadvantages \\
\hline \multirow[t]{2}{*}{$\begin{array}{l}\text { full- } \\
\text { scale }\end{array}$} & $\begin{array}{l}\text { in situ } \\
\text { OWC }\end{array}$ & cyclic & $\begin{array}{l}\text { - } \quad \text { real spectrum of pressure } \\
\text { head as input } \\
\text { - } \quad \text { all transient effects included } \\
\text { no Re- and Ma-number } \\
\text { correction required }\end{array}$ & $\begin{array}{l}\text { - } \\
\text { and hensure input is stochastic } \\
\text { analysis is required } \\
\text { - accuracy of transient flow } \\
\text { rate measurement is low }\end{array}$ \\
\hline & laboratory & steady-state & $\begin{array}{l}\text { no } \mathrm{Re}-\text { and Ma-number } \\
\text { correction required }\end{array}$ & $\begin{array}{ll}\text { - } & \text { transient effects neglected } \\
\text { expensive to mimic installa- } \\
\text { tion effects } \\
\text { test facility prohibitively } \\
\text { expensive }\end{array}$ \\
\hline \multirow[t]{2}{*}{$\begin{array}{l}\text { model- } \\
\text { scale }\end{array}$} & \multirow[t]{2}{*}{ laboratory } & cyclic & $\begin{array}{l}\text { includes some unsteady } \\
\text { effects }\end{array}$ & $\begin{array}{l}\text { test cycle does not neces- } \\
\text { sarily reflect the full spectral } \\
\text { content of full scale pressure } \\
\text { head input } \\
\text { model must be geometrical- } \\
\text { ly similar to full scale tur- } \\
\text { bine } \\
\text { may require Re- and Ma- } \\
\text { number correction } \\
\text { - test rig expensive }\end{array}$ \\
\hline & & steady-state & 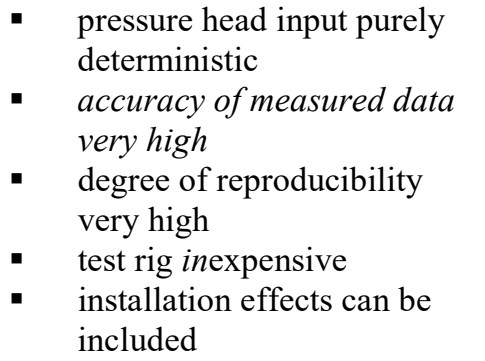 & $\begin{array}{l}\text { - } \quad \text { all transient effects excluded } \\
\text { model must be geometrical- } \\
\text { ly similar to full scale tur- } \\
\text { bine } \\
\text { may require Re- and Ma- } \\
\text { number correction }\end{array}$ \\
\hline
\end{tabular}

Table 2

Test facilities for bidirectional turbines, worldwide

\begin{tabular}{|c|c|c|c|c|c|c|}
\hline \multirow[b]{2}{*}{ location/ref. } & \multirow[b]{2}{*}{\begin{tabular}{|c|} 
rotor \\
diameter
\end{tabular}} & \multirow[b]{2}{*}{$\begin{array}{c}\text { typical turbine } \\
\text { Re/Ma } \\
\end{array}$} & \multicolumn{4}{|c|}{ airflow } \\
\hline & & & unidirectional & bidirectional & steady-state & cyclic \\
\hline $\begin{array}{l}\text { Lisbon, } \\
\text { Portugal/[6] }\end{array}$ & $590 \mathrm{~mm}$ & $\begin{array}{c}3.9 \cdot 10^{5} / \\
0.14\end{array}$ & $\mathrm{x}$ & - & $\mathrm{x}$ & - \\
\hline $\begin{array}{l}\text { Cranfield, } \\
\text { England/[7] }\end{array}$ & $600 \mathrm{~mm}$ & $\begin{array}{c}2.0 \cdot 10^{5} / \\
0.14\end{array}$ & - & $\mathrm{x}$ & - & $\mathrm{x}$ \\
\hline $\begin{array}{l}\text { Limerick, } \\
\text { Ireland/[8] }\end{array}$ & $600 \mathrm{~mm}$ & $\begin{array}{c}5.0 \cdot 10^{5 /} \\
0.2\end{array}$ & - & $\mathrm{x}$ & $\mathrm{x}$ & - \\
\hline $\begin{array}{l}\text { Belfast, } \\
\text { N. Ireland/[9] }\end{array}$ & $200 \mathrm{~mm}$ & $\begin{array}{c}2.5 \cdot 10^{5} / \\
0.17\end{array}$ & $\mathrm{x}$ & $\mathrm{x}$ & $\mathrm{x}$ & $\mathrm{x}$ \\
\hline $\begin{array}{l}\text { Bari, } \\
\text { Italy/[10] }\end{array}$ & $310 \mathrm{~mm}$ & $\begin{array}{c}1.5 \cdot 10^{5} / \\
0.09\end{array}$ & $\mathrm{x}$ & - & $\mathrm{x}$ & - \\
\hline $\begin{array}{l}\text { Saga, } \\
\text { Japan/[11] }\end{array}$ & $435 \mathrm{~mm}$ & $\begin{array}{c}4.25 \cdot 10^{5} / \\
0.16 \\
\end{array}$ & - & $\mathrm{x}$ & - & $\mathrm{x}$ \\
\hline $\begin{array}{l}\text { Kairo, } \\
\text { Egypt/[12] }\end{array}$ & $500 \mathrm{~mm}$ & $\begin{array}{c}3.1 \cdot 10^{5} / \\
0.08\end{array}$ & $\mathrm{x}$ & - & $\mathrm{x}$ & - \\
\hline $\begin{array}{l}\text { Madras, } \\
\text { India/[13] }\end{array}$ & $165 \mathrm{~mm}$ & $\begin{array}{c}0.5 \cdot 10^{5} / \\
0.08\end{array}$ & - & - & $\mathrm{x}$ & - \\
\hline $\begin{array}{l}\text { Siegen, } \\
\text { Germany/ } \\
{[14-16]}\end{array}$ & $400 \mathrm{~mm}$ & $\begin{array}{c}9.4 \cdot 10^{5} / \\
0.36\end{array}$ & $\mathrm{x}$ & - & $\mathrm{x}$ & - \\
\hline
\end{tabular}



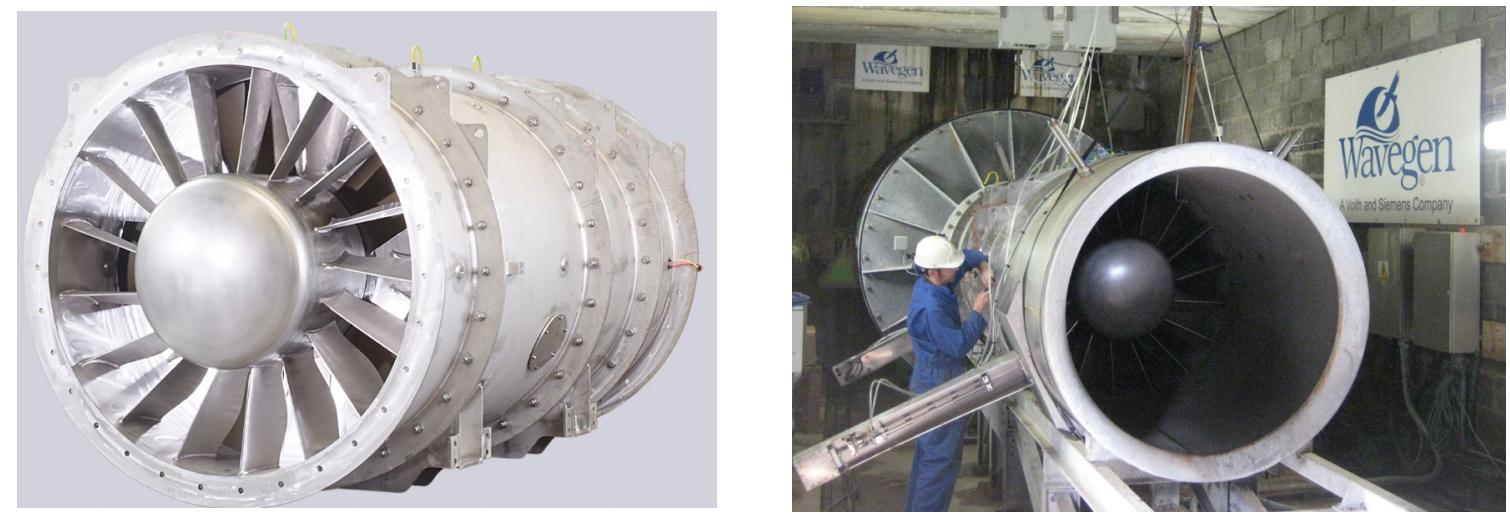

Figure 1. Full-scale dual-stage Wells turbine with guide vanes as operated and tested at LIMPET wave power plant (courtesy of Voith Hydro)

\section{Specification of the University of Siegen turbine performance test facility}

Minimization of installation effects. Differences obtained by testing the same turbine on various test facilities can originate from installation effects. It is known that the characteristic of the inflow to the turbine (velocity profile, statistics of the turbulence) and the pressure recovery at the turbine outlet are affected by upstream and/or downstream elements of the test facility. Inflow and exhaust from and into a large unobstructed space have been used successfully for years in fan performance testing. The unobstructed space can either be a large chamber or the free environment. In contrast to test rigs where the turbine is placed between long duct sections the pressure head can be determined purely from static pressure measurements at the turbine inlet and exhaust. The static pressure is taken at wall tappings of the chamber or in the free environment, i.e. at locations where the flow velocity is zero or negligibly small. Hence, the turbine test facility of the University of Siegen is an inlet and outlet side chamber test facility following ISO 5801 [4] for fan performance testing.

Present and future bidirectional turbines may not be geometrically symmetrical. That means one has to test their performance characteristics for both flow directions. One way is using a unidirectional test rig and turning the turbine, the other providing both flow directions by the test rig and leave the turbine unturned. The University of Siegen test rig described in this contribution is bidirectional. This required more initial design effort but saves time and cost during all subsequent turbine tests.

Model scaling. Essentially the test facility is a laboratory model turbine test rig. All turbines to be tested need to be scaled to a standardized model size. The turbine model size is determined from specified values of Reynolds and Mach number, e.g. for an axial-flow turbine

$$
\operatorname{Re}=\left(\mathrm{C}_{\text {tip }} \mathrm{u}_{\text {tip }}\right) / v
$$

$$
\mathrm{Ma}=\mathrm{u}_{\mathrm{tip}} / \mathrm{c}_{\mathrm{s}}
$$

with the rotor blade chord length $\mathrm{C}_{\mathrm{tip}}$, the rotor circumferential velocity $\mathrm{u}_{\mathrm{tip}}$ at blade tip, the kinematic viscosity $v$ and the speed of sound $\mathrm{c}_{\mathrm{s}}$ of the working fluid.

Rather aiming at the same value of Re for the model test as for full-scale operation, it is common practice to ensure at least a critical value $\mathrm{Re}_{\text {crit }}$, at which the affect of $\mathrm{Re}$ on the turbine performance becomes comparably small. Typical values are $\mathrm{Re}_{\text {crit }}=1$ to $5 \cdot 10^{5}$ (SIGLOCH [17], TAKAO et al. [18]). If necessary model measurements can be corrected for the different Reynolds numbers by recognized methods (International codes for model acceptance tests [19, 20], ACKERET [21], RAGHUNATHAN et al. [22]).The University of Siegen test rig allows testing of models typically with up to $\mathrm{Re}=1 \cdot 10^{6}$.

The Mach number of the model turbine can be kept close to its full-scale value by merely choosing the rotational speed. Here the power of the electric turbine drive/generator and the strength of the rotor are the limiting factors. The full scale LIMPET turbine with a $1.25 \mathrm{~m}$ diameter rotor from Fig. 1 was operated up to $\mathrm{Ma}_{\max } \approx 0.5$, TEASE [23]. The University of Siegen test rig is designed for a maximum Mach number $\mathrm{Ma}=0.5$.

Steady-state operation. A full-scale turbine in an OWC experiences a cyclic variation of pressure head with the volume flow rate changing direction during each period. A simplified analysis yields an estimate of how transient operation modifies the steady-state performance characteristics of a typical OWC turbine. 
The two mechanisms which may alter pressure drop and volume flow rate of a turbine in transient operation are

- the inertia of the accelerated or decelerated fluid in the turbine

- the lift produced by an airfoil in unsteady flow.

Firstly, let us consider the effect of inertia on the differential static pressure across the turbine's in- and outlet. Fig. 2 shows a representation of a turbine as a two-port element. In a first approximation the air is considered incompressible with a density $\rho$. Hence, the mass of a plug of air being moved through the turbine becomes

$$
\mathrm{M}=\rho \mathrm{AL}
$$

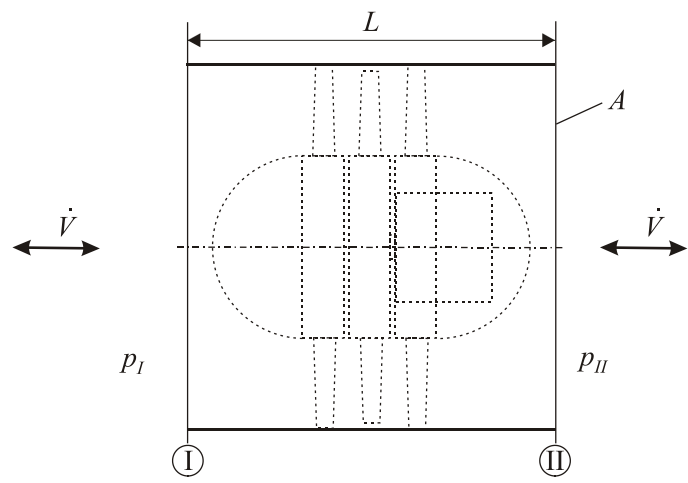

Figure 2. Turbine represented as a two-port element

For the time being the action of the turbine rotor is disregarded. Then conservation of momentum requires

$$
\mathrm{A}\left(\mathrm{p}_{\mathrm{I}}-\mathrm{p}_{\mathrm{II}}\right)\left(\equiv \mathrm{A} \Delta \mathrm{p}_{\text {inertia }}\right)=\mathrm{M} \frac{\mathrm{dc}}{\mathrm{dt}}=\rho \mathrm{L} \frac{\mathrm{d}}{\mathrm{dt}} .
$$

Utilizing the definitions of a flow rate and a pressure (or head) coefficient

$$
\begin{gathered}
\phi \equiv \frac{\frac{\&}{\pi^{2}} \mathrm{D}_{\text {tip }}^{3} \mathrm{n}}{} \\
\psi \equiv \frac{\Delta \mathrm{p}}{\frac{\pi^{2}}{2} \mathrm{D}_{\text {tip }}^{2} \mathrm{n}^{2} \rho}
\end{gathered}
$$

and assuming a sinusoidal variation of flow rate through the turbine with time

$$
\phi=\hat{\phi} \sin (2 \pi \mathrm{ft})
$$

one obtains from eq. (4) the amplitude of the non-dimensional pressure differential due to inertia of the air plug

$$
\hat{\psi}_{\text {inertia }}=\frac{4 \mathrm{Lf}}{\mathrm{D}_{\text {tip }} \mathrm{n}} \hat{\phi} .
$$

Eq. (8) is an estimate of how much the steady-state pressure drop of the turbine is modified due to the transient motion of the mass in the turbine. In section 4 a full scale turbine will be presented with approximate values $\mathrm{L}=2 \mathrm{~m}, \mathrm{D}_{\text {tip }}=1.25 \mathrm{~m}, \mathrm{n}=1600 \mathrm{rpm}$. After RAGHUNATHAN et al. [24] the cycles of typical ocean waves of interest range from $8-15 \mathrm{sec}$, i.e. the frequency is in the order of $\mathrm{f}=0.1 \mathrm{~Hz}$. Operating the turbine cyclically up to its maximum power (i.e. just before stall) on its steady-state performance curve (Fig. 9) the turbine experiences an amplitude $\hat{\phi} \approx 0.2$. As a result, $\hat{\psi}_{\text {inertia }}$ becomes 0.0048 which is, compared to the steady-state pressure head amplitude $\hat{\psi}_{\text {ts }} \approx 1,0$, negligibly small. Of course, if the wave frequency is higher, say $1 \mathrm{~Hz}$, then the inertia may become more relevant.

The second modification of steady-state performance is due to the transient flow around the rotor blades themselves. A classical work by VON KÁRMÁN and SEARS [25] deals with airfoil theory for non-uniform motion. Essentially the variation of flow rate in a turbine with time corresponds to a flow around the blades that is equivalent to a flow as seen by an oscillating airfoil in a free uniform flow. For the latter von Kármán and Sears 
showed that the lift produced by the oscillatory moving airfoil with a chord length $\mathrm{C}$ is not altered as compared to steady-state, when the reduced frequency of the oscillation

$$
\mathrm{f}^{*}=\frac{\pi \mathrm{fC}}{\mathrm{w}_{\infty}}
$$

is much smaller than unity. In case of an axial-flow Wells turbine - purely because of kinematic reasons - the free flow velocity $\mathrm{w}_{\infty}$ is roughly the circumferential velocity of the rotor. Assuming a value of the circumferential Mach number $\mathrm{Ma}=0.5$, a chord length of $\mathrm{C}=0.1 \mathrm{~m}$ and the frequency $\mathrm{f}=0.1 \mathrm{~Hz}$ as before, one obtains $\mathrm{f}^{*}=$ 0.0002 which is indeed much smaller than 1 .

This simplified analysis gives rise to the assumption that steady-state testing is sufficient to describe the performance of bidirectional air turbines for typical OWC systems. Inherent benefits are that (i) the test facility becomes quite simple since a time-accurate cyclic variation of head and through flow is unnecessary, (ii) post processing of experimental data to correct for the dynamic effect of the test rig is not required, and (iii) the problematic measurement of an unsteady and reversing volume flow rate is unnecessary. The latter is of great importance since unsteady volume flow rate measurement is in general very difficult and inaccurate.

Sound power. Sound emitted from OWC systems is of increasing concern. The dominant sound source is always the turbine. Thanks to acoustic treatment of in- and outlet of the test facility and measures for compensating the acoustic effects of the laboratory environment the University of Siegen test facility allows the measurement of the aero-acoustic performance of the (model) turbine.

Tables 3 and 4 summarize the main features of the model test facility at the University of Siegen and the model turbines to be tested.

Table 3

Specification of the model test facility for OWC turbines at the University of Siegen

\begin{tabular}{|l|l|}
\hline Maximum flow rate & $4.3 \mathrm{~m}^{3} / \mathrm{s}$ \\
\hline Maximum chamber pressure & $\pm 10.000 \mathrm{~Pa}$ \\
\hline Rated generator power & $20 \mathrm{~kW}$ \\
\hline Airflow & bidirectional, steady-state \\
\hline Measureable quantities & $\begin{array}{l}\text { volume flow rate, pressure head, shaft torque, rotational speed, } \\
\text { sound pressure (spectral and overall) }\end{array}$ \\
\hline
\end{tabular}

Table 4

Specification of the model turbines that can be tested at the turbine test facility at the University of Siegen

\begin{tabular}{|l|l|}
\hline Nominal rotor diameter & $400 \mathrm{~mm}$ \\
\hline Maximum speed & $8000 \mathrm{rpm}$ \\
\hline Maximum shaft torque & 30 or $50 \mathrm{Nm}$ \\
\hline Achievable Reynolds number & $1 \cdot 10^{6}$ \\
\hline Achievable Mach number & 0.5 \\
\hline
\end{tabular}

\section{Description of the University of Siegen turbine performance test facility}

Overall layout. The overall layout is shown in Fig. 3. The volume flow rate through the facility and hence the turbine to be tested is supplied by an $80 \mathrm{~kW}$ centrifugal fan. Its adjustable speed drive allows setting any value of the volume flow rate. The flow direction is determined by the position of a large two way directional control valve, located close to the fan. The volume flow rate is measured by means of a symmetric Venturi nozzle. The complete airflow supply unit involves various sound attenuator measures. Firstly, the fan and the directional control valve are placed in an acoustic enclosure. The air enters the enclosure through an upper opening with a large splitter attenuator. This prevents acoustic radiation from the fan drive and auxiliary devices into the laboratory environment. Secondly, the flow path to the turbine to be tested is acoustically damped by another huge splitter attenuator integrated into the large chamber. This avoids background noise from entering the turbine.

The large chamber contains screens and honeycombs for reduction of swirl and turbulence in pressure side operation of the rig.

The gauge pressure in the chamber is positive when the test rig is installed at the inlet side of the turbine and negative for outlet side installation. The opposite port of the turbine is always connected to the free laboratory atmosphere. I.e. the turbine either exhausts into the free atmosphere (inlet side installation) or sucks from the free atmosphere (outlet side installation). 

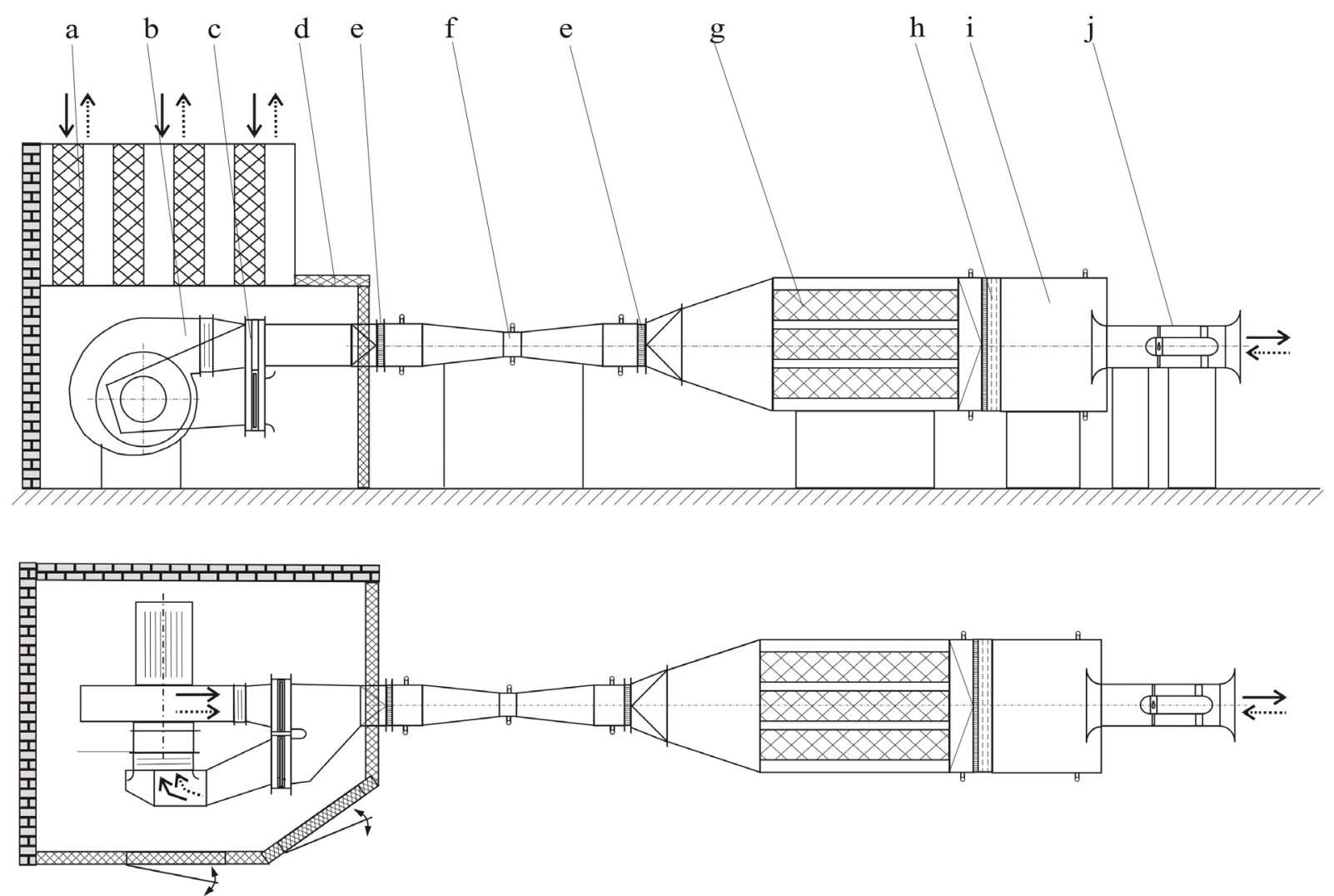

Figure 3. Bidirectional test facility at the University of Siegen - top: side view; bottom: top view: a) splitter attenuator, b) centrifugal fan, c) flow diverter (two way directional flow control valve), d) acoustic enclosure, e) honeycombs, f) calibrated Venturi nozzle, g) splitter attenuator, h) honeycombs and turbulence control screens, i) chamber, j) model turbine

Sensors and data acquisition. The test facility allows direct measurement of total to static pressure head $\Delta \mathrm{p}_{\mathrm{ts}}$, volume flow rate \& , density $\rho$, shaft torque $\mathrm{T}$ and rotational speed $\mathrm{n}$ as well as acoustic sound pressure and power. All relevant measurement positions are displayed within the schematic layouts in Fig. 4.

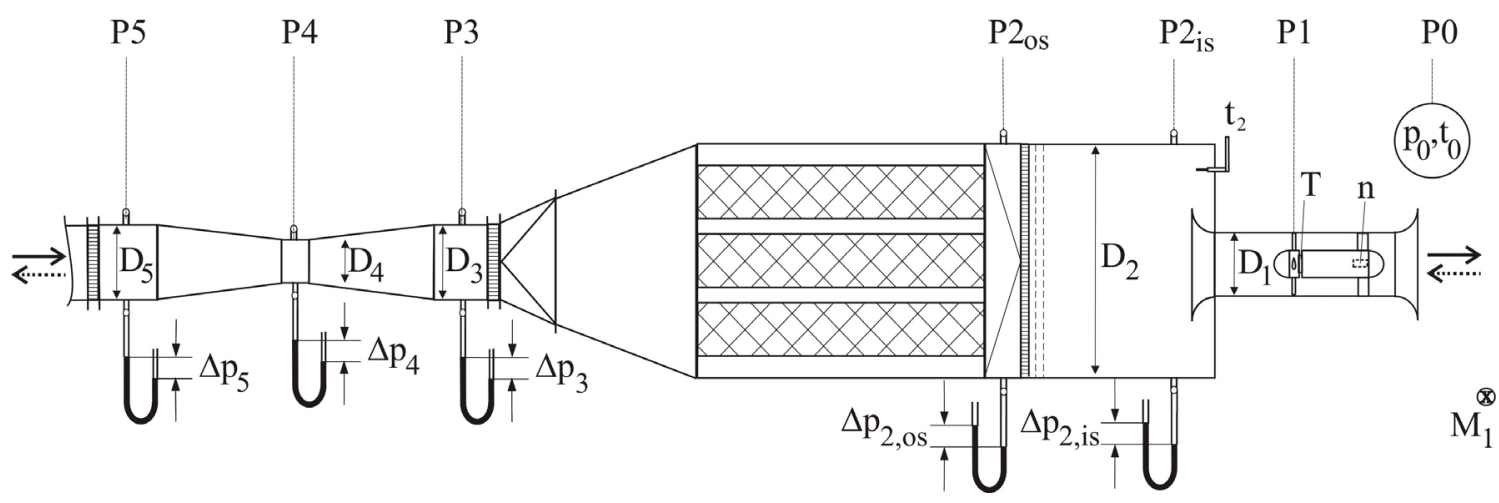

Figure 4. Main dimensions and instrumentation; $\mathrm{D}_{2}=1.25 \mathrm{~m}, \mathrm{D}_{1}=0.4 \mathrm{~m}$

The absolute atmospheric pressure is taken in the lab (P0) from a barometer. All other pressure transducers at the reference planes P2 to P5 sense a gauge pressure $\Delta \mathrm{p}$, with one side being connected to a wall tapping and the other being open to the atmospheric pressure in the lab (reference plane P1 is used for calibration purposes only, see Appendix A). The static pressure in the chamber $\Delta \mathrm{p}_{2}$ is measured for each flow direction downstream of the honeycomb and turbulence screens at $\mathrm{P} 2_{\text {is }}$ and $\mathrm{P} 2_{\text {os }}$, respectively. The chosen position of the two pressure taps follows standards for common fan test rigs. The volume flow rate is determined from the pressure differential $\left(\Delta \mathrm{p}_{4}-\Delta \mathrm{p}_{3}\right)$ or $\left(\Delta \mathrm{p}_{4}-\Delta \mathrm{p}_{5}\right)$, depending on flow direction. The Venturi nozzle has been calibrated carefully for both flow directions, for details see Appendix A.

The dynamic pressure associated with the exhaust of the turbine is always dissipated, either in the free atmosphere of the lab or in the large chamber. Therefore the turbine total to static pressure head 
$\left|\Delta \mathrm{p}_{\mathrm{ts}}\right| \equiv($ total pressure at inlet - static pressure at outlet $)$

is in very good approximation

$$
\left|\Delta \mathrm{p}_{\mathrm{ts}}\right|=\left|\mathrm{p}_{2}-\mathrm{p}_{0}\right|=\left|\Delta \mathrm{p}_{2, \mathrm{os}}\right| \text { or }\left|\Delta \mathrm{p}_{2, \mathrm{is}}\right|
$$

depending on flow direction (the relevant pressure tapping for P2 is always located downstream of the flow straightener to prevent swirl components in the flow distorting the static pressure signals).

For high accuracy of the turbine performance data the density is determined along the flow path at each measurement location. Air temperatures are measured in the lab environment $\left(t_{0}\right)$ and in the chamber $\left(t_{2}\right)$. An adiabatic change of state with an isentropic exponent of air $\kappa=1.4$ is assumed to evaluate air temperature and absolute pressure at other locations.

The shaft torque is measured via a telemetric torque flange connecting turbine rotor directly to the shaft of the generator without additional bearings. An incremental tachometer mounted to the generator shaft senses the turbines rotational speed.

The sound power of the turbine is determined following DIN EN ISO 3741 [26]. For this the sound pressure is measured by a microphone $\left(\mathrm{M}_{1}\right)$ in the laboratory. Within an extensive study SCHENKEL [27] found that (i) one microphone instead of the three according to DIN EN ISO 3741 [26] is sufficient and (ii) a position $2 \mathrm{~m}$ away from the turbine with an angle to the axis of about $45^{\circ}$ is a good compromise for capturing the sound pressure in the acoustic far field without pseudo-sound on the microphone caused by the exhausting jet. Prior to the turbine test a calibrated reference sound source (RSS) is placed at the position of the turbine. The sound pressure at the microphone corresponds unambiguously to the known sound power of the reference sound source. With some efforts even spectra can be obtained by this method. The sound attenuator of the whole test rig were designed such that the background noise level in the entire frequency range of interest is always well below $10 \mathrm{~dB}$ over the sound pressure of the reference sound source and the expected sound emitted from the turbines to be tested. As long as this holds true no correction for background noise is foreseen.

The water cooled synchronous motor-generator is grid connected and controlled by a programmable frequency converter. Two independent safety mechanisms in the test facility protect the turbine from runaway speed.

A control and data acquisition system based on LabView ${ }^{\text {TM }}$ is used to set turbine speed and pressure head (via fan speed) and to collect synchronously all other data.

Fig. 5 shows the test regime in terms of flow-rate and pressure which is provided by the test facility. It is limited by i) the constraints of the measurement instruments, the maximum permissible static pressure (positive or negative) in the chamber and iii) the performance characteristics of the air supplying fan. The differences of the air supply curves are due to losses in the air path which depend on the flow direction.

Further specifications and a detailed discussion of the uncertainties associated with measurements utilizing this University of Siegen turbine performance test facility are compiled in Appendix B.

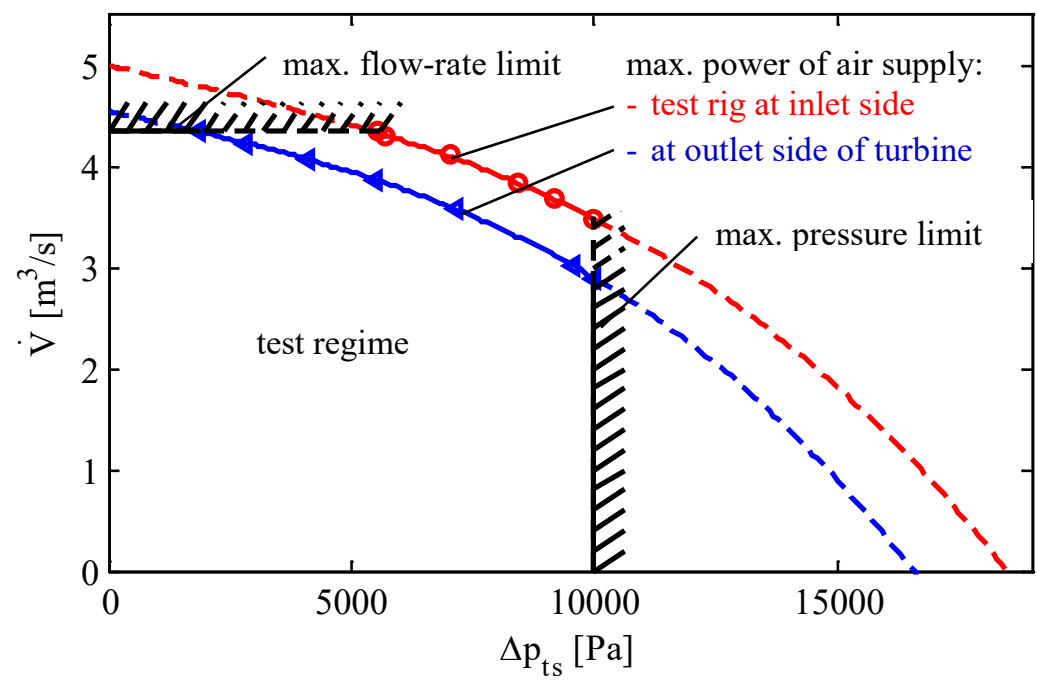

Figure 5. Test regime provided by the test facility 


\section{Exemplary measurements}

This section provides the performance test procedure illustrated by measurements of the full set of aerodynamic and acoustic performance characteristics of three sample turbines. Also the graphical presentation of turbine performance data, found to be useful during turbine development, is shown.

Axial-flow single-rotor Wells turbine without guide vanes. The first sample turbine to be tested is a simple axial-flow Wells turbine without guide vanes, Fig. 6a. It is a single-rotor research reaction turbine, equipped with rotor $\mathrm{N}$ from the study by STARZMANN [28]. Both terminations of the turbine have a bellmouth shape and act either as an inflow nozzle or a small diffuser. A layer of honeycombs is mounted close to the rotor for further homogenization of the inflow to the rotor. The diameter of the rotor $0.4 \mathrm{~m}$, the testing rotational speed is $4000 \mathrm{rpm}$ and kept constant. The resulting Re and Ma numbers are 5.10 $0^{5}$ and 0.24 , respectively.

Two experiments are conducted: i) the turbine is mounted with the test rig installed at either in- or outlet side; to ensure the same flow conditions in the turbine the supporting struts are always downstream of rotor and the flow direction imposed by the test rig is set accordingly; the pressure head is set quasi-steadily in small increments from zero to maximum; ii) the turbine is mounted on the test rig and the direction of the flow fixed; the pressure head is set quasi-steadily in small increments from zero to maximum and reverse.

All experimental data points are non-dimensionalized according to the definitions in Tab. C.1, left column in Appendix C. This set of non-dimensional coefficients is consistent and used in many other turbo-machinery branches. We prefer the pressure head as the independent variable since in an OWC-application the turbines are driven by the varying pressure head that the wave collector imposes on the turbine. If model and full-scale turbine show full or approximate geometrical, kinematic and dynamic similarity, the dimensional characteristics for any $\mathrm{D}_{\text {tip }}, \mathrm{n}$ and $\rho$ can be reconstructed from the non-dimensional.

The left column of Fig. 7 impressively proves that the test facility produces the same performance characteristics of the turbine, irrespective of inlet or outlet side operation. As a result it is justified to rate the University of Siegen test facility as truly bidirectional. The right column shows that depending on the sequence of setting the operating points, i.e. from zero to maximum pressure head or reversed, the turbine characteristics looks different, i.e. the characteristics have a pronounced hysteresis. When the pressure head exceeds a certain value, the turbine (at a fixed rotational) speed stalls, i.e. the volume flow rate through the turbine increases abruptly with no or little conversion of flow into shaft work. (An analogue would be a cog wheel where the cogs break away because of too high a loading.) Another indicator of stall is the sudden increase of sound emitted.

Radial-flow turbine. The second sample turbine to be tested is a radial turbine, Fig. 6b. It is a radial research reaction turbine as described by MOISEL et al. in [29, 30]. Here it becomes evident that a bidirectional test facility is indispensible. Turning the turbine by 180 degrees and mounting it on the test rig is very impractical. Fig. 8 depicts the measured characteristics. This turbine shows characteristics that vary with the flow direction chosen (left column), but nearly no hysteresis is detectable (right column). In most present OWC-applications the nonsymmetrical performance is undesirable which, however, is irrelevant in the context of this paper. As a conclusion the results in Fig. 8 prove that the test facility allows easy and accurate testing of a bidirectional turbine for both flow directions.

Dual-stage axial-flow Wells turbine with guide vanes. The third exemplary test deals with a model of the dual-stage axial-flow Wells turbine with guide vanes as in Fig. 1. The turbine is a advanced Wells turbine with guide vanes (design 'GV6' from STARZMANN et al. [31]). Not a complete model of the full-scale turbine was performance tested on the model test facility, but just one stage consisting of rotor and two adjacent guide vanes. Fig. 9 shows a comparison of full-scale in situ measurements carried out at the LIMPET OWC power plant on the island of Islay, Scotland in October 2011 WRIGHT [32] with scaled up steady-state model performance curves measured on the test facility at the University of Siegen. The full-scale turbine was operated with a Reynolds and Mach number of $2 \cdot 10^{6}$ and 0.31 , the model with $5 \cdot 10^{5}$ and 0.24 , respectively. No Reynolds number correction had been applied when scaling up the model performance curves. The dual-stage arrangement was accounted for by doubling the pressure drop of the single-stage data. Given the scatter in the data, the agreement is very satisfactory. These results underline the usefulness of accurate steady-state model performance testing for the prediction of full-scale transient in situ operation of bidirectional turbines. 
a1)

a2)
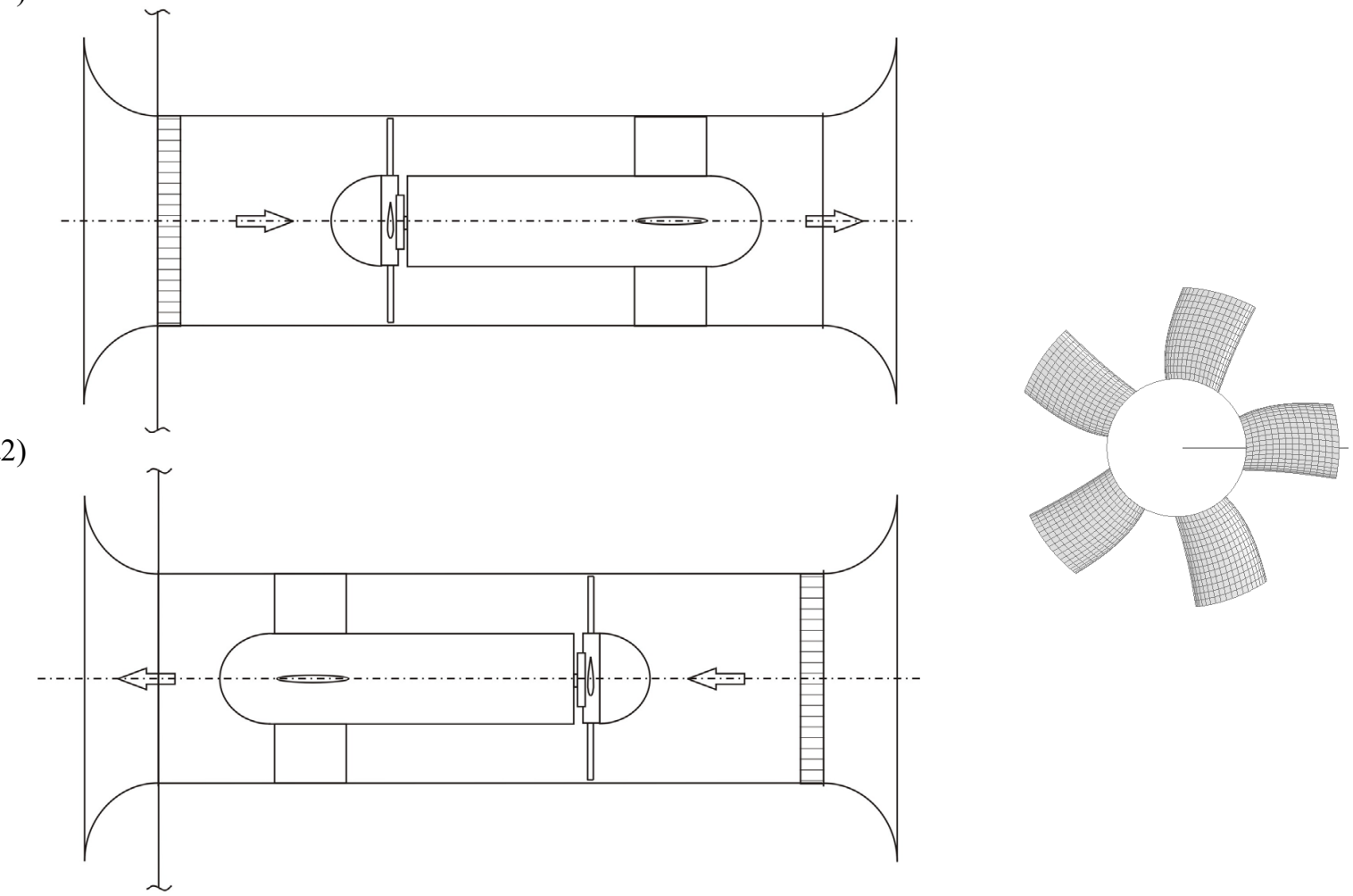

b)
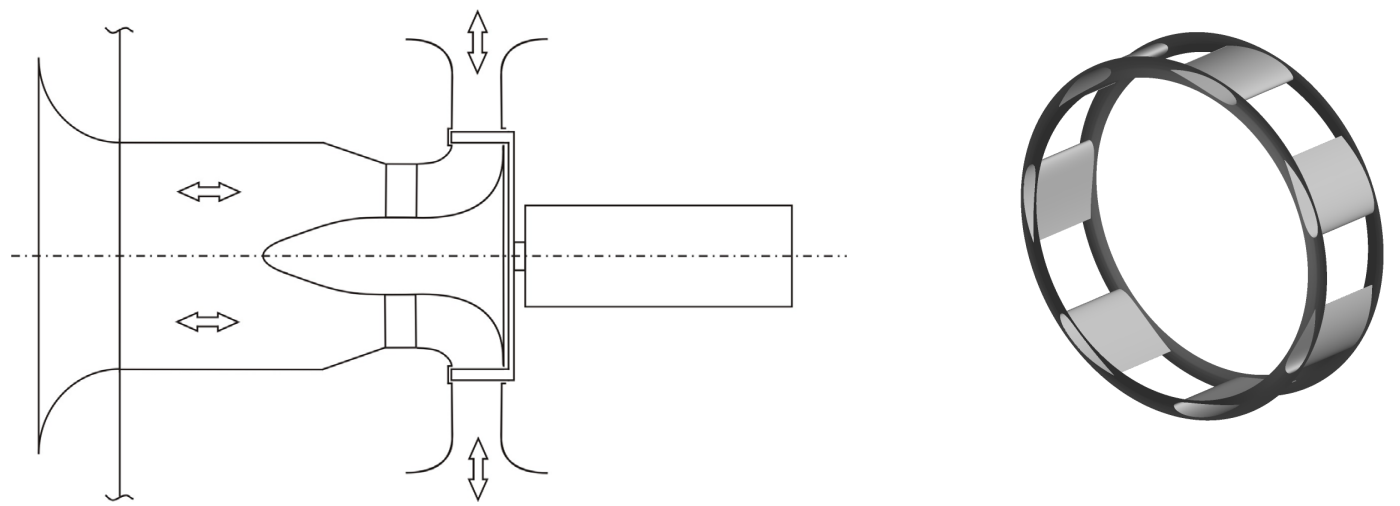

Figure 6. Sample turbines; a) Single-rotor axial-flow Wells turbine (reaction type), a1) inlet side setup, a2) outlet side setup, b) Radialflow turbine (reaction type) 

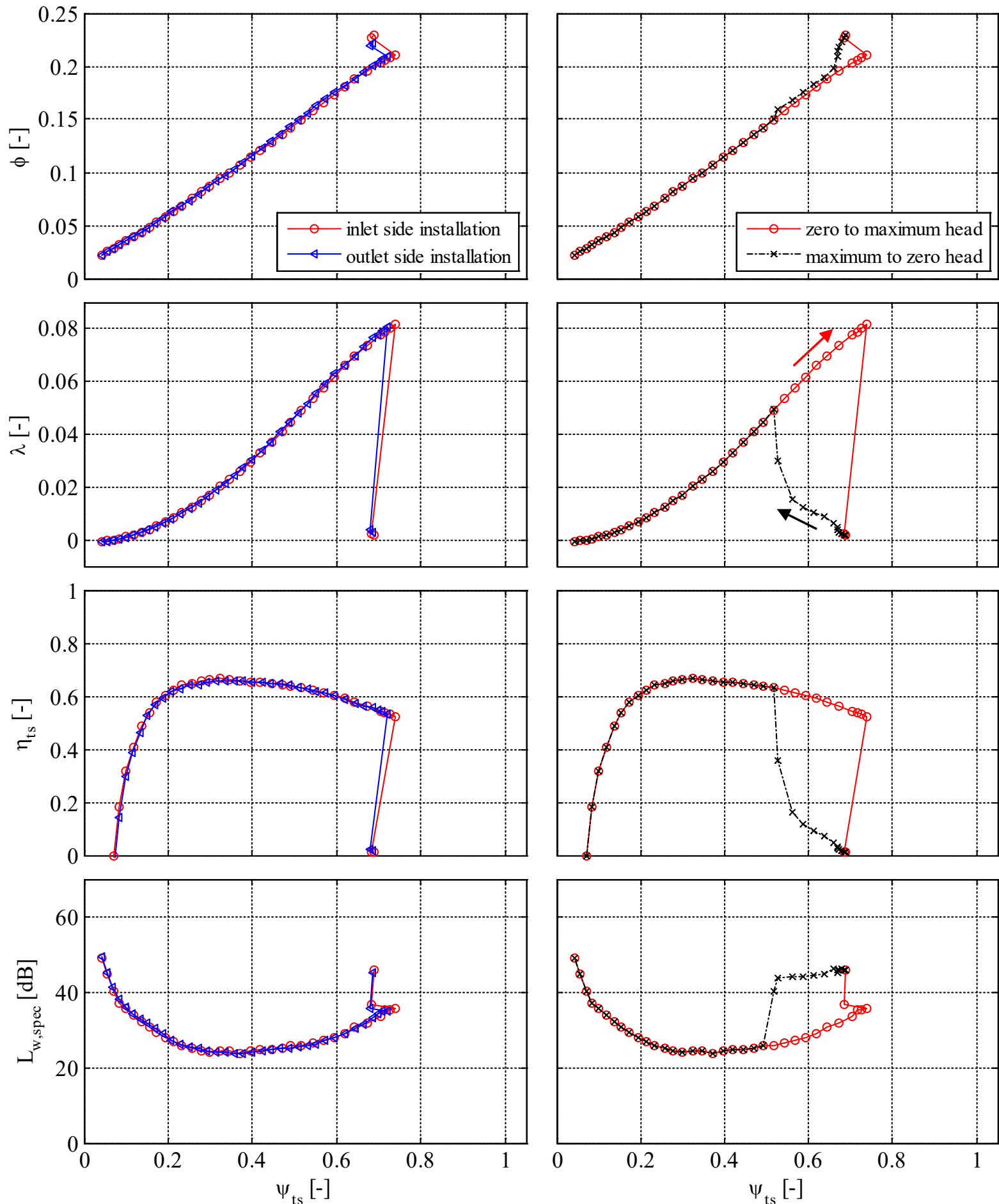

Figure 7. Axial-flow single-rotor Wells turbine without guide vanes: Aero-acoustic performance characteristics; left column: in- vs. outlet side installation of turbine, bidirectional flow; setting of pressure head from zero to maximum; right column: turbine fixed, test with one flow direction (unidirectional flow), setting of pressure head from zero to maximum and reverse; $\operatorname{Re}=5 \cdot 10^{5}$ and $\mathrm{Ma}=0.24$ 

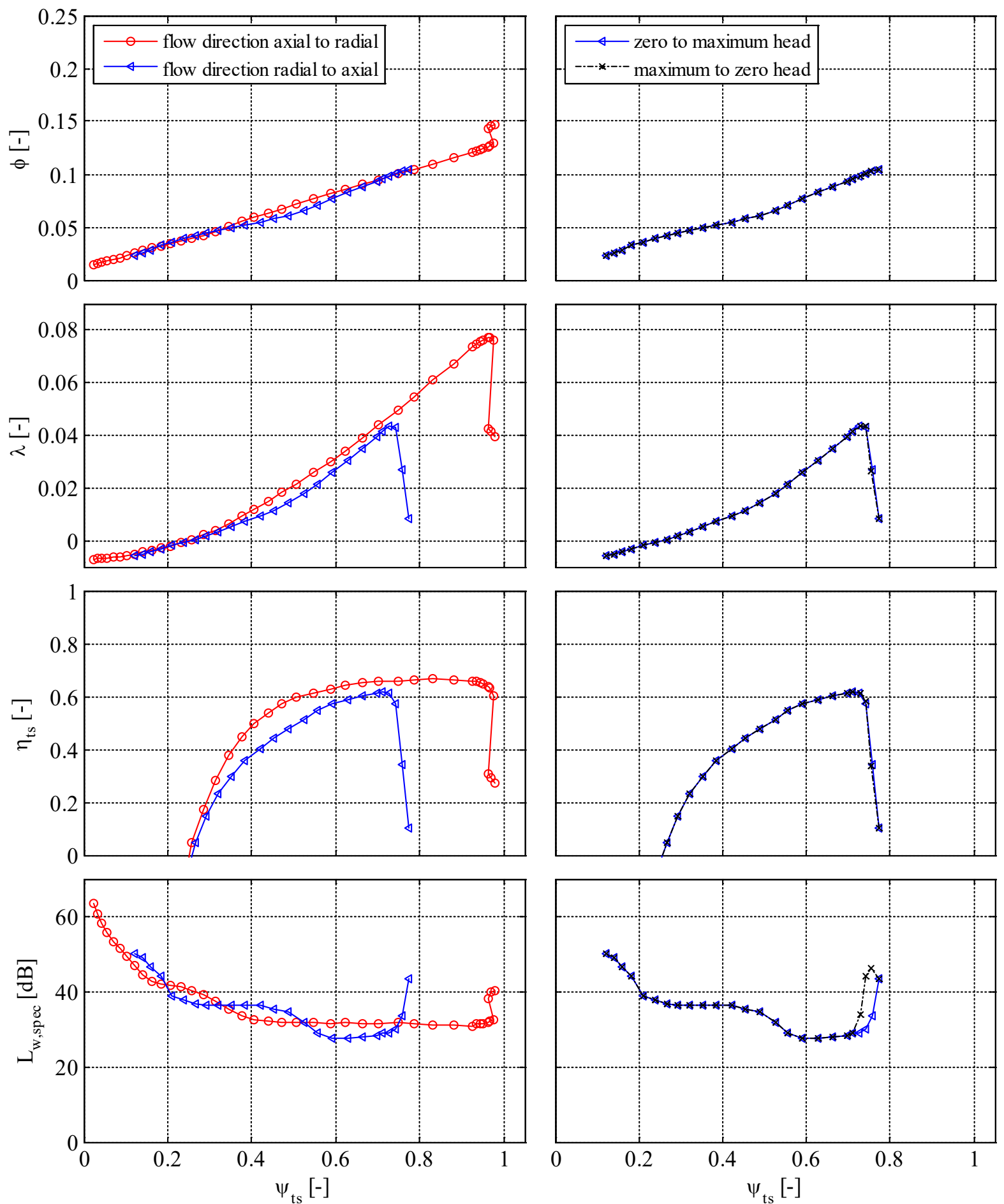

Figure 8. Radial-flow turbine: Aero-acoustic performance characteristics; left column: turbine fixed, test with both flow directions (bidirectional flow), setting of pressure head from zero to maximum; right column: turbine fixed, test with one flow direction (unidirectional flow), setting of pressure head from zero to maximum and reverse; $\mathrm{Re}=4.3 \cdot 10^{5}$ and $\mathrm{Ma}=0.24$ 


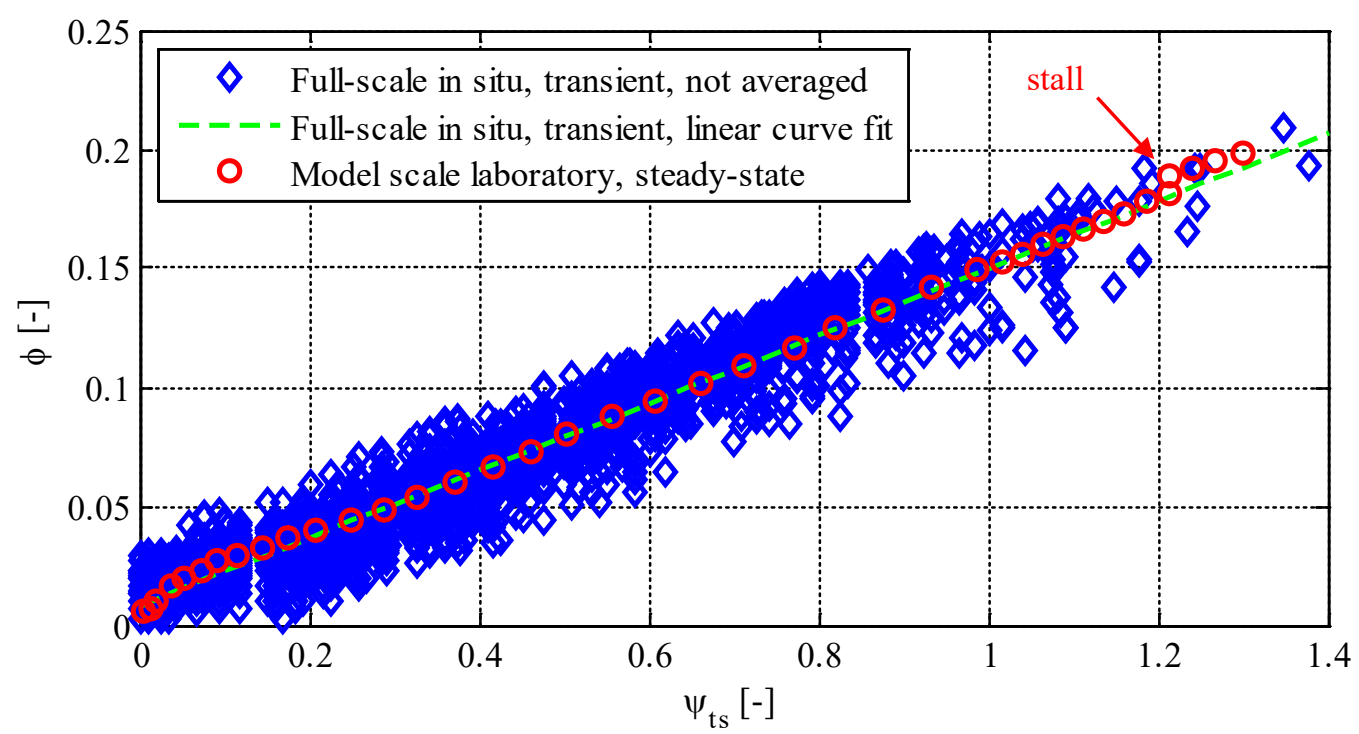

Figure 9. Dual-stage axial-flow Wells turbine with guide vanes: Comparison of model (steady-state) and full-scale in-situ (transient) performance; full-scale data courtesy of Voith Hydro

\section{Conclusion}

The present aerodynamic and aero-acoustic facility for model air turbines performance testing at the University of Siegen has been described. It has been proven that the facility is truly bidirectional, i.e. it produces the same performance characteristics of a turbine, irrespective of pressure or suction side installation of the test rig. Moreover, it has been demonstrated that accurately measured steady-state characteristic of a model turbine or even only an elementary stage of a model turbine is sufficient to predict the in-situ performance of a typical full-scale turbine. It is strongly believed that for typical OWC-application this type of highly accurate steady-state turbine performance test facility is to be preferred over a transient test rig which most likely introduces substantial uncertainties in fundamental quantities such as the volume flow rate through the turbine.

\section{Acknowledgments}

This work is supported by the German Federal Ministry for the Economics and Energy and Voith Hydro (FKZ 0325396. The authors greatly appreciate this support. 


\section{Appendix A: Flow rate calibration}

The arrangement for calibration of the Venturi nozzle is depicted in Fig. A1.

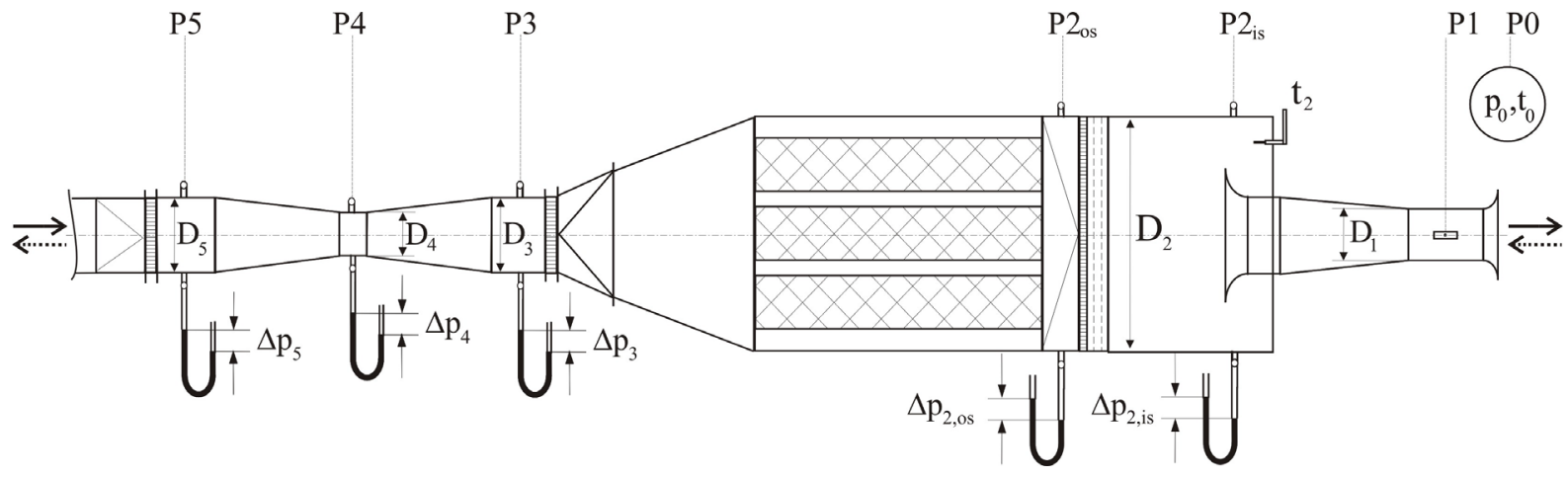

Figure A1. Laboratory test facility - Venturi nozzle calibration setup: $\mathrm{D}_{1}=0.3 \mathrm{~m} ; \mathrm{D}_{2}=1.25 \mathrm{~m} ; \mathrm{D}_{3,5}=0.4 \mathrm{~m} ; \mathrm{D}_{4}=0.2 \mathrm{~m}$

Instead of the turbine a cylindrical duct with a nominal diameter of $\mathrm{D}_{1, \mathrm{c}}=0.3 \mathrm{~m}$ is mounted on the chamber via a bellmouth nozzle and a conical duct section. For reversed flow direction a second bellmouth nozzle acts as inflow device. A hot-wire probe mounted on a traverse is positioned at reference plane P1. Local meridian velocities are measured at $\mathrm{i}=244$ equidistant locations along a straight line trough the duct cross section, with a finer resolution in the boundary layer, Fig. A2. The data sample rate is $10 \mathrm{kHz}$. Time averaging for 2 seconds is applied. Missing data points in the boundary layer from 0 to $2 \mathrm{~mm}$ away from the duct wall have been reconstructed using the logarithmic wall function, see e.g. VDI 2640 [33]. The "true" volume flow rate through reference plane $\mathrm{P} 1$ is obtained as

$$
\&_{1}^{\&}=2 \pi \int \mathrm{c}_{\mathrm{m}} \mathrm{rdr}
$$

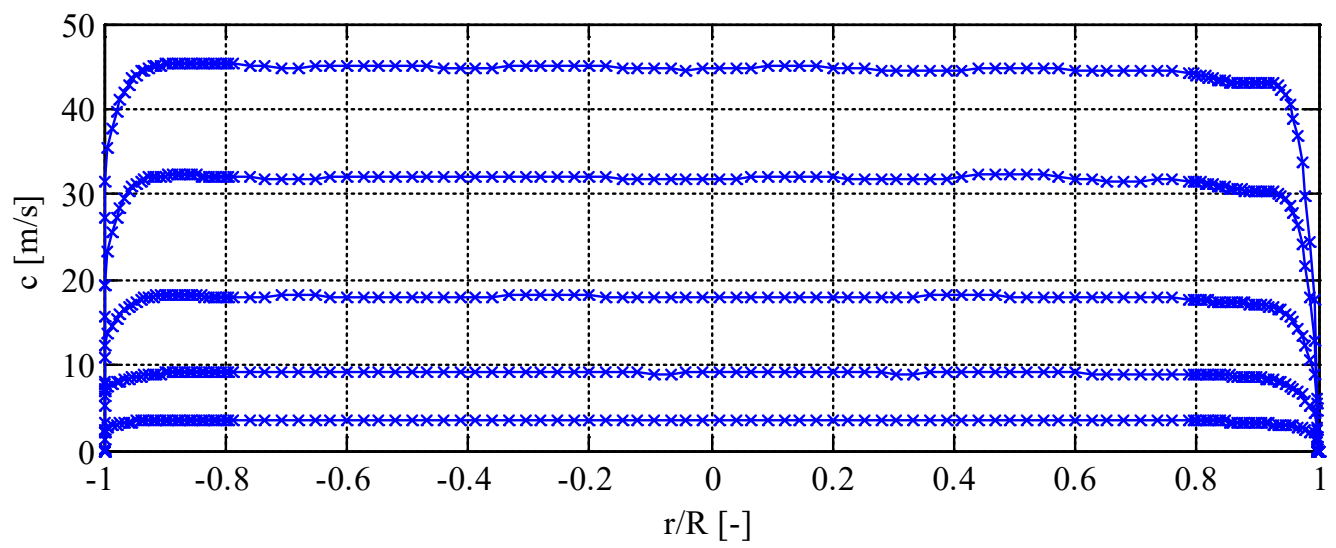

Figure A2. Hot-wire measured velocity profiles in reference plane P1 with near wall correction for different through flows

The air density in P1 is estimated as

$$
\rho_{1}=\frac{p_{1, \mathrm{is} / \mathrm{os}}}{\mathrm{R}_{\mathrm{Air}} \mathrm{T}_{2}},
$$

with $\mathrm{p}_{1, \mathrm{os}}=\mathrm{p}_{0}-\frac{\rho}{2} \mathrm{c}_{1}^{2}, \mathrm{p}_{1, \mathrm{is}}=\left(\mathrm{p}_{0}+\Delta \mathrm{p}_{2}\right)-\frac{\rho}{2} \mathrm{c}_{1}{ }^{2}$ and the absolute temperature in the chamber $\mathrm{T}_{2}=\mathrm{t}_{2}+273 \mathrm{~K}$. The mass flow rate $1 \boldsymbol{\&}_{1}$ through $\mathrm{P} 1$ then becomes

$$
1 \mathbf{k}_{1}=\rho_{1} \mathbb{\&}_{1}^{\mathbf{k}}
$$


Simultaneously, depending on the flow direction, the differential pressure in the venturi nozzle $\Delta \mathrm{p}_{N, i s}=\Delta \mathrm{p}_{5}-$ $\Delta \mathrm{p}_{3}$ or $\Delta \mathrm{p}_{N, o s}=\Delta \mathrm{p}_{4}-\Delta \mathrm{p}_{3}$ is recorded. According to ISO 5167-4 [34] the mass flow rate through the Venturi nozzle is

$$
\boldsymbol{1}_{\mathrm{N}}=\frac{\mathrm{C}}{\sqrt{1-\beta^{4}}} \varepsilon \frac{\pi}{4} \mathrm{D}_{4}^{2} \sqrt{2 \Delta \mathrm{p}_{\mathrm{N}} \rho_{\mathrm{N}}} \text {. }
$$

It is a function of nozzle coefficient $C$, the Venturi diameter ratio $\beta=\mathrm{D}_{4} / \mathrm{D}_{3,5}$, the compression coefficient $\varepsilon$, the local air density $\rho_{\mathrm{N}}$ at the respective upstream plane P3 or P5 and differential pressure measured at the nozzle $\Delta \mathrm{p}_{\mathrm{N}}$. The nozzle compression coefficient is the ratio of the absolute pressure at the inlet and middle section

$$
\varepsilon=\frac{\mathrm{p}_{4}}{\mathrm{p}_{3 / 5}}=\frac{\mathrm{p}_{0}+\Delta \mathrm{p}_{4}}{\mathrm{p}_{0}+\Delta \mathrm{p}_{3 / 5}}
$$

The air density in P3 or P5 is given by

$$
\rho_{\mathrm{N}}=\frac{\mathrm{p}_{0}+\Delta \mathrm{p}_{3 / 5}}{\mathrm{R}_{\text {Air }} \mathrm{T}_{2}}
$$

Assuming no leakage in the complete test rig the nozzle coefficient $\mathrm{C}$ can now be evaluated as

$$
\mathrm{C}\left(\operatorname{Re}_{\mathrm{N}}\right)=\frac{1 \boldsymbol{\&}_{1} \sqrt{1-\beta^{4}}}{\varepsilon \frac{\pi}{4} \mathrm{D}_{4}^{2} \sqrt{2 \Delta \mathrm{p}_{\mathrm{N}} \rho_{\mathrm{N}}}}
$$

as a function of the local Reynolds number $\operatorname{Re}_{\mathrm{N}}$

$$
\operatorname{Re}_{\mathrm{N}}=\frac{\mathrm{c}_{3 / 5} \mathrm{D}_{3 / 5}}{v}=\frac{41 \boldsymbol{\&}_{1}}{\pi \mathrm{D}_{3 / 5} \rho_{\mathrm{N}} \mathrm{v}}
$$

This process is carried out for both flow directions. The result of the calibrations process is displayed in Figure A3. Neglecting the effect of Reynolds number would lead to an unacceptable error in flow rate. But as expected the curve fits, used for all turbine tests, are nearly independent of flow direction through the Venturi nozzle.

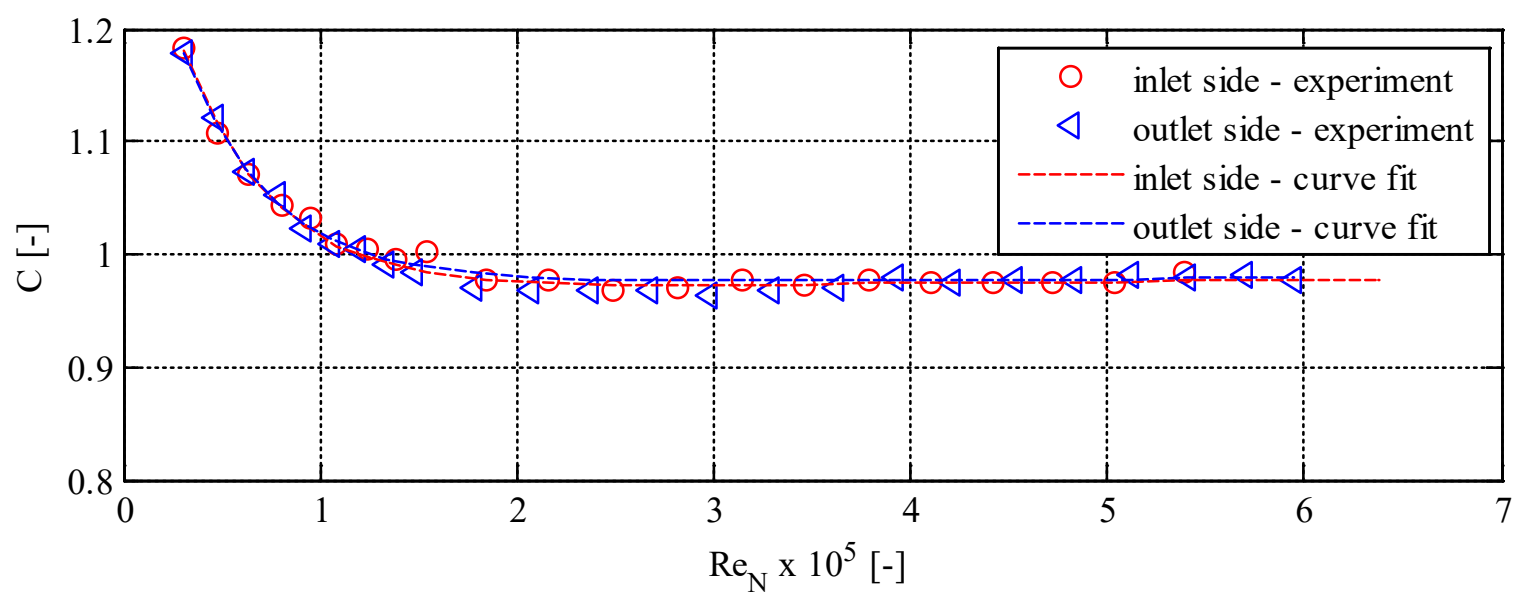

Figure A3. Nozzle coefficient for the Venturi nozzle used

Eventually when testing a turbine the mass flow rate through the turbine is determined from measured quantities as

$$
\mathbf{R}=\frac{\mathrm{C}}{\sqrt{1-\beta^{4}}} \varepsilon \frac{\pi}{4} \mathrm{D}_{4}^{2} \sqrt{2 \Delta \mathrm{p}_{\mathrm{N}} \rho_{\mathrm{N}}}
$$

Iteration is required since $\mathrm{C}$ and $\rho_{\mathrm{N}}$ depend on Reynolds number or mass flow rate. Given the density of air $\rho$ relevant for the turbine the volume flow rate through the turbine becomes 


$$
\mathbb{k}=\frac{1 \mathbb{8}}{\rho}
$$

It is good practice to take $\rho$ as the average $\left(\rho_{2}+\rho_{0}\right) / 2$ with

$$
\rho_{0}=\frac{\mathrm{p}_{0}}{\mathrm{R}_{\text {Air }} \mathrm{T}_{0}} \text { and } \rho_{2}=\frac{\mathrm{p}_{0}+\Delta \mathrm{p}_{2}}{\mathrm{R}_{\text {Air }} \mathrm{T}_{2}}
$$

\section{Appendix B: Uncertainty analysis}

Uncertainties in Measurements. The procedure to determine the measurement uncertainty as presented in this paper is based on EDEN [35], DIN 1319-3 [36] and DIN 1319-4 [37] (equivalent to the European standard EN 13005). The entire measurement chain is subject to random and bias uncertainties. Any quantity $\mathrm{Y}=\mathrm{f}\left(\mathrm{X}_{1}, \mathrm{X}_{2}, \ldots, \mathrm{X}_{\mathrm{m}}\right)$ is determined from $\mathrm{m}$ individual measurements with individual measurement instruments. The maximum random error $U_{R}\left(X_{i}\right)$ for any specific measurement instrument is taken from the manufacturer's technical data sheet. Each random variable $X_{m}$ is measured with the instrument $n$ times and the sample mean value and standard deviation are determined. Since $n$ is limited, the random uncertainty $U_{R}\left(X_{i}\right)$ is determined following the STUDENT-t distribution which for large numbers of $\mathrm{n}$ approaches the normal distribution. If all input parameters for the quantity $\mathrm{Y}$ are uncorrelated and the maximum random errors $\mathrm{U}_{\mathrm{R}}\left(\mathrm{X}_{\mathrm{i}}\right)$ are available, a combined random uncertainty of $\mathrm{Y}$ is determined employing the law of propagation of uncertainty:

$$
\mathrm{U}_{\mathrm{C}, \mathrm{R}}=\sqrt{\left(\frac{\partial \mathrm{f}}{\partial \mathrm{X}_{1}} \mathrm{U}_{\mathrm{R}}\left(\mathrm{X}_{1}\right)\right)^{2}+\left(\frac{\partial \mathrm{f}}{\partial \mathrm{X}_{2}} \mathrm{U}_{\mathrm{R}}\left(\mathrm{X}_{2}\right)\right)^{2}+\ldots+\left(\frac{\partial \mathrm{f}}{\partial \mathrm{X}_{\mathrm{m}}} \mathrm{U}_{\mathrm{R}}\left(\mathrm{X}_{\mathrm{m}}\right)\right)^{2}}
$$

Bias uncertainties are more difficult to quantify as they are related to inappropriate dimensioning of test rig components (e.g. too small a chamber) and inappropriate installation of sensors. Explicitly the test facility and its instrumentation presented in this article are designed to minimize bias errors by following actions:

- layout of the test facility and positioning of the sensors following ISO 5801 [4]

- continuous monitoring and correction of zero offsets

- careful calibration of the volume flow rate Venturi nozzle, see Appendix A

- air densities correctly determined at each reference plane

- direct telemetric torque measurement between rotor and generator shaft without additional bearings

Facilities Aerodynamic Measurement Equipment. The random uncertainties of the measurement equipment in use are given in Tab. B.1.

\begin{tabular}{|c|c|c|c|c|}
\hline Instrument & Variable & Range & $\begin{array}{l}U_{R, F S} \\
{[\% \text { of full scale] }}\end{array}$ & $\begin{array}{l}\mathrm{U}_{R} \\
\text { [of reading] }\end{array}$ \\
\hline Torque flange & $\mathrm{T}$ & $0 \ldots 30 \mathrm{Nm}$ & 0.1 & $0.03 \mathrm{Nm}$ \\
\hline Tachometer & $\mathrm{n}$ & $0 \ldots 8000 \mathrm{rpm}$ & 0.1 & $8 \mathrm{rpm}$ \\
\hline Thermometer & $\mathrm{t}$ & $0 \ldots 100^{\circ} \mathrm{C}$ & 1 & $1^{\circ} \mathrm{C}$ \\
\hline Differential pressure sensor at Venturi nozzle & $\begin{array}{l}\Delta \mathrm{p}_{\mathrm{N}} \\
\Delta \mathrm{p}_{\mathrm{N}}\end{array}$ & $\begin{array}{l} \pm 500 \mathrm{~Pa} \\
\pm 5.000 \mathrm{~Pa}\end{array}$ & $\begin{array}{l}0.01 \\
0.01\end{array}$ & $\begin{array}{l}0.5 \mathrm{~Pa} \\
5 \mathrm{~Pa}\end{array}$ \\
\hline Differential pressure sensor chamber & $\begin{array}{l}\Delta \mathrm{p}_{2} \\
\Delta \mathrm{p}_{2}\end{array}$ & $\begin{array}{l} \pm 1.000 \mathrm{~Pa} \\
\pm 15.000 \mathrm{~Pa}\end{array}$ & $\begin{array}{l}0.01 \\
0.01\end{array}$ & $\begin{array}{l}1 \mathrm{~Pa} \\
15 \mathrm{~Pa}\end{array}$ \\
\hline Nozzle inlet pressure sensors & $\Delta \mathrm{p}_{3,5}$ & $\pm 10.000 \mathrm{~Pa}$ & 0.1 & $100 \mathrm{~Pa}$ \\
\hline
\end{tabular}

Table B.1

Facility measurement equipment: Specifications and maximum random uncertainty

Uncertainty in aerodynamic characteristics. The combined uncertainty of the non-dimensional performance coefficients $\phi, \psi_{\mathrm{ts}}, \lambda$ and $\eta_{\mathrm{ts}}$ are determined from the uncertainties in Tab. B.1, HORSTHEMKE [38]. In Fig. B.1 the aerodynamic performance characteristics of the Wells and Radial turbine are plotted with an error band. Obviously the uncertainties in flow-rate $\phi$ and power coefficient $\lambda$ are rather small wherein the combined uncertainty of the efficiency measurement becomes clearly visible at small pressure heads $\psi_{\text {ts }}$ within the aerodynamic characteristics. This can be traced back to the limited relative uncertainty at low volume flow rates and torque measurement even with the high precision measurement equipment employed. For the relevant operational range around maximum peak efficiency ('opt') and maximum power production ('maxpower') the relative uncertainty is reduced below about $2 \%$ for the Wells turbine and below about $1 \%$ for the radial turbine. A de- 
tailed summary of the cumulated relative uncertainties $\mathrm{U}_{\mathrm{C} \text {,rel }}$ in percentage points at discrete operating points of both turbines is compiled in Tab. B.2.

Table B.2: Relative aerodynamic measurement uncertainties at discrete operating points

\begin{tabular}{|c|c|c|c|c|c|}
\hline Turbine & Operating point & $\mathbf{U}_{C, \text { rel }, \phi}[\%]$ & $\mathbf{U}_{\mathrm{C}, \mathrm{rel}, \Psi}[\%]$ & $\mathbf{U}_{\mathbf{C}, \text { rel }, \lambda}[\%]$ & 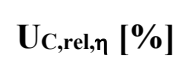 \\
\hline \multirow[t]{2}{*}{ Wells N } & Optimum & 0.82 & 1.34 & 1.64 & 2.26 \\
\hline & Max. power & 0.69 & 0.84 & 0.76 & 1.32 \\
\hline \multirow[t]{2}{*}{ Radial } & Optimum & 0.82 & 0.68 & 0.98 & 1.46 \\
\hline & Max. power & 0.81 & 0.68 & 0.98 & 1.43 \\
\hline
\end{tabular}
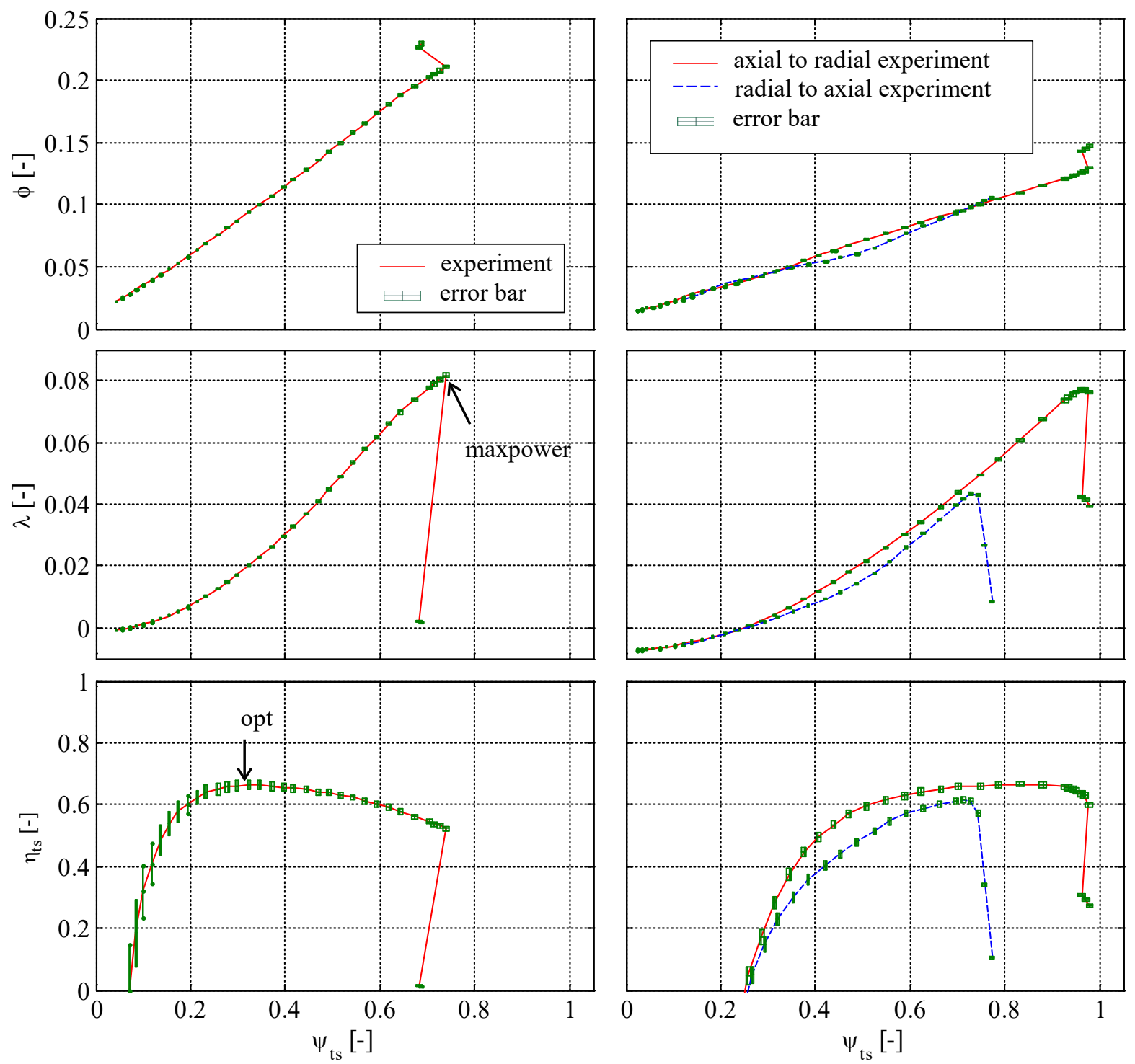

Figure B.1. Aerodynamic performance characteristics with error bars; left column: Wells turbine N, right column: Radial turbine

Uncertainty in aeroacoustic characteristics. A comparison method according to DIN EN ISO 3741 [26] is employed to determine the sound power $\mathrm{L}_{\mathrm{w}}$ of the rotors via a calibrated reference sound source (RSS). In contrast to the standard, only one microphone is used to record time signals of the sound pressure. SCHENKEL [27] showed that the acoustic measurements at the test facility are within precision grade 2, according to DIN EN ISO 3747 [39]. Based on the method employed, the uncertainty regarding the overall sound power level is estimated to be $\mathrm{U}_{\mathrm{C}, \mathrm{Lw}}=2 \mathrm{~dB}$ as in STARZMANN [28]. 


\section{Appendix C: Dimensionless coefficients}

Table C.1: Non-dimensional coefficients

\begin{tabular}{|c|c|c|c|}
\hline (2) & Present study & $\begin{array}{l}\text { Definitions as used in other publica- } \\
\text { tions }\end{array}$ & Relationship \\
\hline $\begin{array}{l}\text { Flow (rate) } \\
\text { coefficient }\end{array}$ & $\phi=\frac{\pi^{2}}{\frac{\pi^{2}}{4} D_{\text {tip }}^{3} \mathrm{n}}$ & & \\
\hline $\begin{array}{l}\text { Pressure } \\
\text { coefficient }\end{array}$ & $\psi=\frac{\Delta \mathrm{p}}{\frac{\pi^{2}}{2} \rho \mathrm{D}_{\text {tip }}^{2} \mathrm{n}^{2}}$ & $\Delta \mathrm{p}^{*}=\frac{\Delta \mathrm{p}}{\pi^{2} \rho \mathrm{D}_{\mathrm{tip}}^{2} \mathrm{n}^{2}}$ & $\Delta \mathrm{p}^{*}=\frac{1}{2} \psi$ \\
\hline $\begin{array}{l}\text { Power } \\
\text { coefficient }\end{array}$ & $\lambda=\frac{\mathrm{P}_{\text {shaft }}}{\frac{\pi^{4}}{8} \mathrm{D}_{\text {tip }}^{5} \mathrm{n}^{3} \rho}$ & $\mathrm{P}^{*}=\frac{\mathrm{P}_{\text {shaft }}}{\frac{\pi^{3}}{4} \mathrm{D}_{\text {tip }}{ }^{5} \mathrm{n}^{3} \rho}$ & $P^{*}=\frac{\pi}{2} \lambda$ \\
\hline Efficiency & $\eta=\frac{P_{\text {shaft }}}{\&_{\Delta \mathrm{p}}}\left(=\frac{\lambda}{\phi \psi}\right)$ & & \\
\hline $\begin{array}{l}\text { Specific } \\
\text { sound power }\end{array}$ & $\mathrm{L}_{\mathrm{w}, \mathrm{spec}}=\mathrm{L}_{\mathrm{w}}-10 \lg \frac{\frac{\&}{\&_{0}}}{\&_{0}}-20 \lg \frac{\Delta \mathrm{p}_{\mathrm{ts}}}{\Delta \mathrm{p}_{0}}$ & & \\
\hline
\end{tabular}




\section{References}

[1] S. L. Dixon and C. A. Hall, 2010, Fluid Mechanics and Thermodynamics of Turbomachinery, 6th ed. Boston: Butterworth Heinemann.

[2] S. Raghunathan and C. P. Tan, 1985, "Effect of blade profile on the performance of the Wells selfrectifying air turbine," International Journal of Heat and Fluid Flow, vol. 6, pp. 17-22.

[3] M. Inoue, K. Kaneko, and T. Setoguchi, 1986, "Determination of optimum geometry of wells turbine rotor for wave power generator - part II - considerations for practical use," in Current practices and new technology in ocean engineering, McGuinness, ed. New York Ocean engineering division, ASME, pp. 441-446.

[4] ISO 5801: 2014, "Industrial fans - Performance testing using standardized aiways," in ISO 5801, I.-I. O. f. Standardization.

[5] ISO 13347-1-4:2004, "Industrial Fans - Determination of Fan Sound Power Levels under Standardized Laboratory Conditions.

[6] A. F. O. Falcao, L. M. C. Gato, and E. P. A. S. Nunes, 2013, "A novel radial self-rectifying air turbine for use in wave energy converters. Part 2. Results from model testing," Renewable Energy, vol. 53, pp. 159-164.

[7] S. J. Herring and G. Lard, 2007, "A New Test Facility for evaluating turbines for use in OWC power plants " in 7th European Wave and Tidal Energy Conference Porto, Portugal.

[8] A. Thakker and R. Abdulhadi, 2008, "The performance of Wells turbine under bi-directional airflow," Renewable Energy, vol. 33, pp. 2467-2474.

[9] S. Raghunathan, C. P. Tan, and O. O. Ombaka, 1985, "Performance of the Wells self-rectifying air turbine," Aeronautical Journal, vol. 89, pp. 369-379.

[10] S. M. Camporeale, P. Filianoti, and M. Torresi, 2011, "Performance of a Wells Turbine in an OWC Device in Comparison to Laboratory Tests," in 9th European Wave and Tidal Energy Conference, Southampton, UK.

[11] M. Takao, M. Suzuki, T. Setoguchi, B. Pereiras, and F. Castro, 2010, "Radial Turbine with Pitchcontrolled Guide Vanes for Wave Energy Conversion," in 3rd International Conference on Ocean Energy, $r$, , Bilbao, Spain.

[12] H. A. Heikal, A. A. Hafiz, N. N. Bayomi, and M. H. Ahmed, 2003, "Theoretical and experimental investigation on the Wells turbine performance," in 7th Conference on Theoretical \& Applied Mechanics, Cairo, Egypt, pp. 213-233.

[13] K. Mala, J. Jayaraj, V. Jayashankar, T. M. Muruganandam, S. Santhakumar, M. Ravindran, M. Takao, T. Setoguchi, K. Toyota, and S. Nagata, 2011, "A twin unidirectional impulse turbine topology for OWC based wave energy plants - Experimental validation and scaling," Renewable Energy, vol. 36, pp. 307-314.

[14] R. Starzmann, 2012, Aero-Acoustic Analysis of Wells Turbines for Ocean Wave Energy Conversion vol. 7. Duesseldorf: VDI.

[15] R. Starzmann and T. H. Carolus, 2014, "Model-based selction of full-scale Wells turbines for ocean wave energy conversion and prediction of their arodynamic and acoustic performances," Journal of Power and Energy, vol. 288, pp. 2-16.

[16] R. Starzmann, C. Moisel, T. Carolus, K. Tease, and R. Arlitt, 2013, "Assessment method of sound radiated by cyclically operating Wells turbines," International Journal of Marine Energy, vol. 2, pp. 1227.

[17] H. Sigloch, 2013, Strömungsmaschinen: Grundlagen und Anwendungen vol. 5. München: Hanser

[18] M. Takao, A. Thakker, R. Abdulhadi, and T. Setoguchi, 2006, "Effect of blade profile on the performance of a large-scale Wells turbine for wave-energy conversion," International Journal of Sustainable Energy, vol. 25, pp. 53-61.

[19] IEC 497, 1976, International Code for Model Acceptance Tests of Storage Pumps.

[20] IEC 193, 1965, International Code for Model Acceptance Test of Hydraulic Turbines.

[21] E. Mühlemann, 1948, "Zur Aufwertung des Wirkungsgrades von Überdruck Wasserturbinen," Schweiz. Bauzeitung, vol. 66, p. 331.

[22] S. Raghunathan, 1995, "The Wells air turbine for wave energy-conversion," Progress in Aerospace Sciences, vol. 31, pp. 335-386.

[23] K. Tease, Jan 2013, "Personal communication," ed. Inverness, UK.

[24] S. Raghunathan and O. O. Ombaka, 1985, "Effect of frequency of air flow on the performance of the Wells turbine," International Journal of Heat and Fluid Flow, vol. 6, pp. 127-132.

[25] T. von Kármán and W. R. Sears, 1938 J. of the Aeronautical Sciences, vol. Vol. 5, pp. pp. 379 -390.

[26] DIN EN ISO 3741:2010, "Bestimmung der Schallleistungspegel von Geräuschquellen aus Schalldruckmessungen - Hallraumverfahren der Genauigkeitsklasse 1. 
[27] B. Schenkel, 2010, "Schallleistungsmessung an einer Wellsturbine mittels einer Bezugsschallquelle," Diplomarbeit Nr. A10-3/1 am Institut für Fluid- und Thermodynamik, Institut für Fluid- und Thermodynamik, Universität Siegen, Germany.

[28] R. Starzmann, 2012, "Model-scale Wells Turbines investigated at the University of Siegen," IFT University of Siegen, Siegen, Internal Report B10 004 A

[29] C. Moisel and R. Starzmann, 2013, "Aerodynamic design and numerical investigation of a new radial bi-directinal turbine for wave energy conversion," presented at the 10th European Wave and Tidal Energy Conference (EWTEC), Aalborg, Denmark.

[30] C. Moisel and T. H. Carolus, 2014, "Experimental loss analysis on a model-scale radial bidirectional air-turbine for wave energy conversion," presented at the 1st International Conference on Renewable Energies Offshore (RENEW), Lisbon, Portugal.

[31] R. Starzmann, T. Zhu, C. Moisel, and T. H. Carolus, 2012, "Aero-Acoustic Analysis of the Wells Turbine with Guide Vanes," presented at the 4th International Conference on Ocean Energy, Dublin.

[32] A. Wright, 2011, "Personnel correspondence," C. Moisel, Ed., ed. Inverness, UK: Voith Hydro Wavegen.

[33] VDI/VDE 2640, 1993, "Netzmessungen in Strömungsquerschnitten," ed: Verein Deutscher Ingenieure, p. 87.

[34] DIN EN ISO 5167-4:2003, "Durchflussmessungen von Fluiden mit Drosselgeräten in voll durchströmten Leitungen mit Kreisquerschnitt - Teil 4: Venturirohre, Beuth Verlag, Berlin.

[35] K. Eden and H. Gebhard, 2014, Dokumentation in der Mess- und Prüftechnik. Messen - Auswerten Darstellen Protokolle - Berichte - Präsentationen: Springer Vieweg

[36] DIN 1319-3:1996, "Grundlagen der Messtechnik - Auswertung von Messungen einer einzelnen Meßgröße, Messunsicherheiten", Beuth Verlag, Berlin.

[37] DIN 1319-4:1999, "Grundlagen der Messtechnik - Auswertung von Messungen, Messunsicherheiten", Beuth Verlag, Berlin.

[38] J. Horsthemke, 2014, "Experimentelle Untersuchung einer radialen bidirektionalen Wellenenergieturbine," Bachelorarbeit, Institut für Fluid- und Thermodynamik, Universität Siegen, Siegen.

[39] DIN EN ISO 3747:2010, "Bestimmung der Schallleistungspegel von Geräuschquellen aus Schalldruckmessungen. 